\title{
Anticoagulation after Spontaneous Intraparenchymal Hemorrhage in Patients with Mechanical Heart Valves and Concomitant Atrial Fibrillation
}

\author{
Jennifer H. Kang', \\ Michael W. Lutz ${ }^{1}$ \\ Michael L. James ${ }^{1,2}$
}

Allison Gibson ${ }^{1}$

Ovais Inamullah ${ }^{1}$

Gary Clay Sherrill ${ }^{3}$

\begin{abstract}
Address for correspondence Jennifer $\mathrm{H}$. Kang, Department of Neurology, Duke University Medical Center, 2301 Erwin Road, Durham, NC 27710, United States (e-mail: jenkang1018@gmail.com).
\end{abstract}

\begin{abstract}
Keywords

- anticoagulation

- intracerebral hemorrhage

- mechanical heart valve

- atrial fibrillation

Aim Patients with mechanical heart valves and coexisting atrial fibrillation (AFib-MHV) who suffer an intraparenchymal hemorrhage (IPH, defined as bleeding solely within the brain parenchyma and/or ventricle) are at a high risk of thromboembolism without anticoagulation. Data are lacking regarding the safety of early re-initiation of anticoagulation in these patients.

Patients and Methods We performed a descriptive, single-institution retrospective analysis of patients with AFib-MHV who suffered a non-traumatic, supratentorial IPH between July 2013 and June 2017. We analyzed the patients and IPH characteristics, anticoagulation and antiplatelet use, the occurrence of thrombotic and hemorrhage complications, and discharge disposition. We described the timing of initiation of anticoagulation and outcomes after IPH while in-patient.

Results Six patients with AFib-MHV suffered a spontaneous IPH. Four were initiated on anticoagulation prior to discharge, of whom two were initiated within 3 days post-hemorrhage. These patients suffered no bleeding complications and were discharged home with a modified Rankin Scale of 1.

Conclusion Patients with AFib-MHV who suffer a spontaneous IPH are a rare population to study. Further studies to guide the management of restarting anticoagulation in this select population are warranted.
\end{abstract}

\section{Introduction}

Patients with mechanical heart valves and coexisting atrial fibrillation (AFib-MHV) who suffer an intraparenchymal hemorrhage (IPH, defined as bleeding solely within the brain parenchyma and/or ventricle) are at a considerably high risk of thromboembolism when off their anticoagulation. ${ }^{1-3}$
There are no studies determining when it is safe to restart anticoagulation after IPH for this select population. ${ }^{14,5}$ Neurologists, cardiologists, and intensivists must weigh the risk of re-bleeding against the high risk of thromboembolism, and due to the lack of data, decisions must be made with little evidence, only that extrapolated from studies of patients with atrial fibrillation or mechanical heart valves (MHV) alone. published online

October 24, 2021
Dol https://doi.org/ $10.1055 / \mathrm{s}-0041-1735653$ ISSN 2348-0548 (c) 2021. Indian Society of Neuroanaesthesiology and Critical Care. This is an open access article published by Thieme under the terms of the Creative Commons Attribution-NonDerivative-NonCommercial-License, permitting copying and reproduction so long as the original work is given appropriate credit. Contents may not be used for commercial purposes, or adapted, remixed, transformed or built upon. (https://creativecommons.org/licenses/by-nc-nd/4.0/).

Thieme Medical and Scientific Publishers Pvt. Ltd. A-12, 2nd Floor, Sector 2, Noida-201301 UP, India 
The European Society of Cardiology (ESC) and American Heart Association/American Stroke Association (AHA/ASA) emphasize the need for earlier anticoagulation for patients with MHV due to their higher risk of embolism than patients with atrial fibrillation or other indications for anticoagulation, but there are no clear guidelines as to when it is most safe. ${ }^{1-3,6}$ At best, the ESC states it "may be safe" to start systemic heparin 3 days after IPH and switch to a vitamin $\mathrm{K}$ antagonist (VKA) at 7 days. ${ }^{1-3,6}$

Patients with AFib-MHV have a higher risk of thromboembolic events compared with patients with high-risk atrial fibrillation $\left(\mathrm{CHA}_{2} \mathrm{DS}_{2}-\mathrm{VAS}_{\mathrm{c}}>2\right)^{7}$ and those with $\mathrm{MHV}$ with sinus rhythm. ${ }^{8}$ The emphasis of early anticoagulation for patients with MHV is extrapolated to those with AFib-MHV but without better evidence of risk factors associated with good outcomes, the worry of IPH expansion after reinitiating anticoagulation will strongly persist.

To address the gap in the literature, we performed a retrospective analysis of patients admitted to our institution with non-traumatic supratentorial IPH in patients with AFib-MHV and compared those who were started on anticoagulation while in-patient with those who were not. We characterized the patients and their IPH and evaluated outcomes in terms of thromboembolic events, bleeding rates, and disposition. We hypothesized that anticoagulation within a few days post-IPH would be tolerated in select patients of this high-risk group.

\section{Patients and Methods}

We performed a single-institution retrospective analysis of patients with non-traumatic, supratentorial IPH. This study was approved by the Duke University Institutional Review Board. Adult patients $\geq 18$ years old who were admitted to any Duke University Hospital for non-traumatic, supratentorial IPH between July 1, 2013, and June 20, 2017, were retrospectively identified from the DENDRITe database (DukE Neurocritical Care Patient Data ReposITory) and the Get With The Guidelines Stroke Database. Based on past medical history, we identified patients who had the following indications for anticoagulation prior to their hospitalization: atrial fibrillation or MHV. For this type of study, formal consent was not required.

The following data were extracted from the Duke electronic health record: patient's medical history; admission laboratory values; systolic blood pressure at the time of presentation to the hospital; IPH characteristics (including etiology, location-deep, hemispheric, lobar, multiple); intracerebral hemorrhage (ICH) score ${ }^{9}$; if applicable, type of neurosurgical intervention performed; code status; and if applicable, type, timing, and dose of anticoagulation or antiplatelet agent reinitiated. By chart review, we determined the occurrence of thromboembolic complications, defined as ischemic stroke, transient ischemic attack, myocardial infarction, valvular thrombus, or peripheral arterial embolism, and the occurrence of bleeding complications, defined as hematoma expansion $>33 \%$ or $>6 \mathrm{~mL},{ }^{10}$ any major extracranial hemorrhage, or any overt, actionable sign of hemorrhage

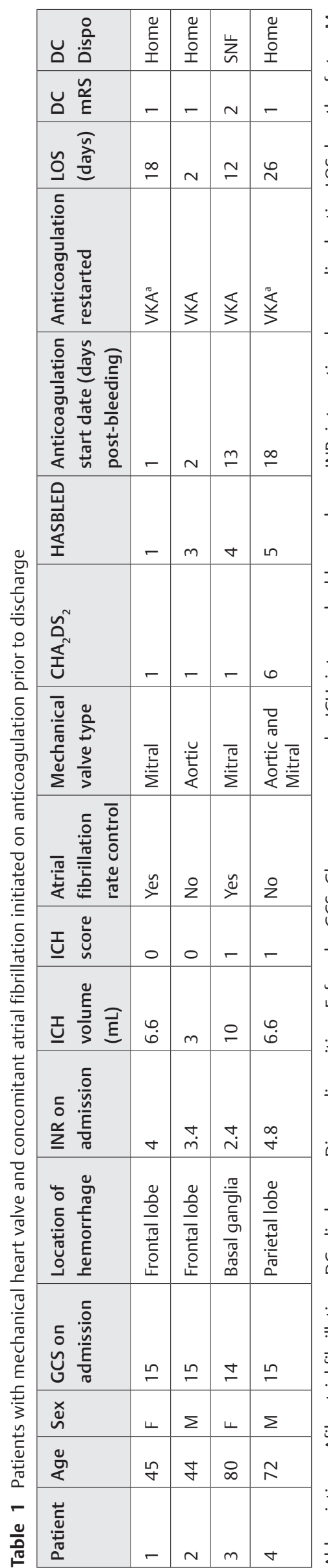


(i.e., more bleeding than would be expected for a clinical circumstance, including bleeding found by imaging alone) that met at least one of the following criteria: (1) requiring nonsurgical, medical intervention by a healthcare professional, (2) leading to the increased level of care, or (3) prompting evaluation, according to Bleeding Academic Research Consortium Type 2 or greater. ${ }^{11}$ We also reviewed the patient's chart for the modified Rankin Scale (mRS) at discharge ${ }^{12}$; discharge disposition; and date of death, if applicable. Hematoma volume was calculated based on the $\mathrm{ABC} / 2$ method..$^{13}$ The following were calculated based on extracted data whenever applicable: for patients with atrial fibrillation, and $\mathrm{CHA}_{2} \mathrm{DS}_{2}$ VASc and HAS-BLED scores ${ }^{7,14}$ and for patients with a thromboembolic or hemorrhagic complication, time from IPH to complication and time from anticoagulation (if started) until complication.

\section{Results}

Non-traumatic supratentorial IPH was identified in 395 patients admitted to the Duke Health System during the study period, of whom 6 patients were identified to have Afib-MHV and were analyzed.

All patients suffered an IPH in the setting of anticoagulation and received reversal agents to correct their coagulopathy. All patients were managed medically according to the ASA/AHA Guidelines for the Management of Spontaneous Intracerebral Hemorrhage, ${ }^{2}$ which included treatment of coagulopathy and thrombocytopenia and acute lowering of blood pressure to $<140 \mathrm{~mm} \mathrm{Hg}$ until stable intracranial imaging. One patient underwent hematoma evacuation out of concern for abscess as the etiology of the hemorrhage (-Table 1, Patient 1). The final pathology report revealed only blood products. One patient underwent placement of an extra-ventricular drain (-Table 2, Patient 2).

Four patients were initiated on anticoagulation prior to discharge (median 8.5 days post-IPH, range 1-18), and two of these patients were initiated on anticoagulation within 3 days post-IPH ( - Table $\mathbf{1}$ ). Patients started on early anticoagulation had small hematoma volumes ( $<10 \mathrm{~mL}, \mathrm{~mL}$ ), were relatively young ( $<50$ years old), and tolerated anticoagulation without any hemorrhagic complications. There were no thromboembolic complications in these patients.

Two patients were not initiated on anticoagulation and died during their admission ( - Table 2 ). These patients were older ( $>60$ years) with large hematoma volumes ( $>30 \mathrm{~mL}$ ). One died of multiorgan failure; the other was made comfort care.

\section{Discussion}

This is a descriptive study evaluating solely patients with AFib-MHV who suffered non-traumatic, supratentorial IPH and were reinitiated on anticoagulation while in-patient. As far as we know, this is the first study specific to this population to date. Four patients were started on therapeutic anticoagulation prior to hospital discharge, and two within 3 days after IPH. The etiology of IPH for all was predominantly due to therapeutic anticoagulation and all patients' coagulopathies were adequately reversed. Patients initiated on early anticoagulation were younger ( $<50$ years old) and had smaller hematoma volumes ( $<10 \mathrm{~mL})$. No patients suffered hemorrhagic complications of initiating anticoagulation. There was no institutional protocol to guide decision-making for whom and when to restart anticoagulation.

This study is unique from prior studies regarding atrial fibrillation and MHV because of its focus on patients with only concomitant Afib-MHV, who should be uniquely studied because of their different risk factors of both thromboembolic and bleeding complications off anticoagulation compared with patients with sole atrial fibrillation or MHV. ${ }^{8}$ Kuramatsu et al's study, ${ }^{8}$ the largest analysis of patients with MHVs who suffered vitamin-K antagonist associated IPH, revealed a statistically significant higher risk of bleeding complications and a non-statistically significant but higher risk of thromboembolic complications off anticoagulation for those with MHV-afib ( $n=21)$ compared with those with sinus rhythm $(n=50) .{ }^{8}$ There was no difference in bleeding complications when both groups were therapeutically anticoagulated. ${ }^{8}$ The authors recommended waiting until day 14 to re-initiate anticoagulation for patients with MHV, except for patients with MHV-afib, who had a higher risk of thromboembolic complications. For these patients, anticoagulation 6 days post-bleeding seemed reasonable. ${ }^{8}$

Our patient population was also unique from prior studies because of its focus on patients who suffered only spontaneous, supratentorial IPH. A systematic review by Chandra et al. that has influenced guidelines determined that initiating heparin infusion within 3 days and oral anticoagulation within 7 days after intracerebral hemorrhage can be safe for patients with prosthetic heart valves ${ }^{2,6}$; however, their data were extrapolated from studies of patients with various indications for anticoagulation and various types of intracerebral hemorrhage, not just IPH. ${ }^{2,6}$ Given its incomparable rate of re-bleeding and different pathophysiology than traumatic

Table 2 Patients with a mechanical heart valve and concomitant atrial fibrillation not initiated on anticoagulation

\begin{tabular}{|l|l|l|l|l|l|l|l|l|l|l|l|l|l|}
\hline Patient & Age & Sex & $\begin{array}{l}\text { GCS on } \\
\text { admis- } \\
\text { sion }\end{array}$ & $\begin{array}{l}\text { Location } \\
\text { of hemor- } \\
\text { rhage }\end{array}$ & $\begin{array}{l}\text { INR on } \\
\text { admis- } \\
\text { sion }\end{array}$ & $\begin{array}{l}\text { ICH } \\
\text { vol- } \\
\text { ume } \\
(\mathrm{mL})\end{array}$ & $\begin{array}{l}\text { ICH } \\
\text { Score }\end{array}$ & $\begin{array}{l}\text { Atrial } \\
\text { fibrilla- } \\
\text { tion rate } \\
\text { control } \\
\text { agent }\end{array}$ & $\begin{array}{l}\text { Mechanical } \\
\text { valve type }\end{array}$ & CHA $_{2} \mathrm{DS}_{2}$ & HASBLED & $\begin{array}{l}\text { Why no anti- } \\
\text { coagulation }\end{array}$ & $\begin{array}{l}\text { Time from } \\
\text { IPH until } \\
\text { death } \\
\text { (days) }\end{array}$ \\
\hline 1 & 84 & M & 10 & Temporal & 4.2 & 32 & 3 & No & Mitral & 7 & 2 & Critical illness & 10 \\
\hline 2 & 85 & M & $5 T$ & Frontal & 5 & 60 & 5 & Yes & Aortic & 7 & 5 & $\begin{array}{l}\text { Comfort care } \\
\text { within } 48 \mathrm{~h}\end{array}$ & 2 \\
\hline
\end{tabular}

Abbreviations: GCS, Glasgow coma scale; ICH, intracerebral hemorrhage; INR, international normalized ratio; IPH, intraparenchymal hemorrhage; $\mathrm{mL}$, milliliters. 
hemorrhages or subarachnoid hemorrhages, patients with IPH should not be concomitantly studied with other types of intracerebral hemorrhage when determining the safe timing of re-initiating anticoagulation post-bleeding.

For the time being, patients with Afib-MHV can only be anticoagulated with VKAs. There is currently no approval for the newer, direct oral anticoagulants for these indications. VKA-associated IPH can be reversed by several agents. Uncorrected coagulopathy in vitamin $\mathrm{K}$ antagonist-associated IPH is associated with worse outcomes, namely increased frequency of hematoma enlargement and rate of in-hospital mortality. ${ }^{15}$ In light of this, the impact of the Kuramatsu et al's study is dampened by the fact that international normalized ratio (INR) reversal was achieved in only $25 \%$ of all patients. ${ }^{8,15}$ Kuramatsu et al's conclusion to wait 6 days based on the hemorrhagic risk profile was likely skewed, given the known association between inadequate correction of coagulopathy and increased bleeding complication rate.

We acknowledge that a sample of two patients initiated on early anticoagulation is the main limitation of this study, in addition to its retrospective design. Given the small sample size and a sparse number of adverse events, we could not evaluate significant risk factors for those who tolerated early anticoagulation or risk of thromboembolic events if anticoagulation was delayed. Moreover, as a retrospective study, there was no systematic method of identifying thromboembolic and bleeding complications. A complication would have only been identified if the primary provider was concerned enough to order a diagnostic study.

This study highlights the rarity of this population. Prior studies emphasize the fact that the population is understudied, and there is a need for more robust data for this population of patients whose thromboembolic risk off anticoagulation is greater than those with sole MHV or Afib. A prospective or larger retrospective study is needed to inform the management and guidelines of this select population who face no option to stay off anticoagulation. Our study did show tolerance of early anticoagulation (within 3 days) in young patients with small hematoma volumes and coagulopathy-associated etiology of their IPH, which was corrected. Age, hematoma volume, and correction of coagulopathy are suggested risks factors to explore in future studies. Uncontrolled hypertension, poor neurological status, and the presence of cerebral amyloid angiopathy are also other known risk factors for recurrent IPH and worse outcomes. Although these were not a concern in our patient group, these could also be explored as additional risk factors., ${ }^{2,16-19}$ Long-term risk of re-hemorrhage should also be studied.

\section{Conclusion}

Patients with MHV and coexistent atrial fibrillation who suffer spontaneous IPH are a rare population to study, and further research regarding risk factors for early anticoagulation in these patients is warranted to best inform the management of these patients with a high risk of thromboembolism off anticoagulation. We report two patients who tolerated early anticoagulation (within 3 days) after suffering a spontaneous IPH attributed to anticoagulation. We note that their small hematoma size, young age, adequate reversal of coagulopathy, and no comorbid hypertension or amyloid angiopathy may have been favorable risk factors for early anticoagulation.

\section{Conflict of Interest}

M.W.L. reports personal fees fromZinfandel Pharmaceutics, outside the submitted work. C.B.S. has received a speaker's honorarium from UCB and Eisai, and consulting fees from Marinus and Minnetronix, outside the submitted work. The other authors report no conflict of interest.

\section{References}

1 Halvorsen S, Storey RF, Rocca B, et al. ESC Working Group on Thrombosis. Management of antithrombotic therapy after bleeding in patients with coronary artery disease and/or atrial fibrillation: expert consensus paper of the European Society of Cardiology Working Group on Thrombosis. Eur Heart J 2017;38(19):1455-1462

2 Hemphill JC II, Greenberg SM, Anderson CS, et al. American Heart Association Stroke Council; Council on Cardiovascular and Stroke Nursing; Council on Clinical Cardiology. Guidelines for the management of spontaneous intracerebral hemorrhage: a guideline for healthcare professionals from the American Heart Association/American Stroke Association. Stroke 2015;46(7):2032-2060

3 Steiner T, Al-Shahi Salman R, Beer R, et al. European Stroke Organisation. European Stroke Organisation (ESO) guidelines for the management of spontaneous intracerebral hemorrhage. Int J Stroke 2014;9(7):840-855

4 Becattini C, Sembolini A, Paciaroni M. Resuming anticoagulant therapy after intracerebral bleeding. Vascul Pharmacol 2016;84:15-24

5 Olesen JB, Lip GY, Hansen ML, et al. Validation of risk stratification schemes for predicting stroke and thromboembolism in patients with atrial fibrillation: nationwide cohort study. BMJ 2011;342:d124

6 Chandra D, Gupta A, Grover V, Kumar Gupta V. When should you restart anticoagulation in patients who suffer an intracranial bleed who also have a prosthetic valve? Interact Cardiovasc Thorac Surg 2013;16(4):520-523

7 Lip GY, Nieuwlaat R, Pisters R, Lane DA, Crijns HJ. Refining clinical risk stratification for predicting stroke and thromboembolism in atrial fibrillation using a novel risk factor-based approach: the euro heart survey on atrial fibrillation. Chest 2010;137(2):263-272

8 Kuramatsu JB, Sembill JA, Gerner ST, et al. Management of therapeutic anticoagulation in patients with intracerebral haemorrhage and mechanical heart valves. Eur Heart J 2018;39(19):1709-1723

9 Hemphill JC II, Bonovich DC, Besmertis L, Manley GT, Johnston SC. The ICH score: a simple, reliable grading scale for intracerebral hemorrhage. Stroke 2001;32(4):891-897

10 Dowlatshahi D, Demchuk AM, Flaherty ML, Ali M, Lyden PL, Smith EE; VISTA Collaboration. Defining hematoma expansion in intracerebral hemorrhage: relationship with patient outcomes. Neurology 2011;76(14):1238-1244

11 Mehran R, Rao SV, Bhatt DL, et al. Standardized bleeding definitions for cardiovascular clinical trials: a consensus report from the Bleeding Academic Research Consortium. Circulation 2011;123(23):2736-2747 
12 Rankin J. Cerebral vascular accidents in patients over the age of 60. II. Prognosis. Scott Med J 1957;2(5):200-215

13 Kothari RU, Brott T, Broderick JP, et al. The ABCs of measuring intracerebral hemorrhage volumes. Stroke 1996;27(8): 1304-1305

14 Pisters R, Lane DA, Nieuwlaat R, de Vos CB, Crijns HJ, Lip GY. A novel user-friendly score (HAS-BLED) to assess 1-year risk of major bleeding in patients with atrial fibrillation: the Euro Heart Survey. Chest 2010;138(5):1093-1100

15 Kuramatsu JB, Gerner ST, Schellinger PD, et al. Anticoagulant reversal, blood pressure levels, and anticoagulant resumption in patients with anticoagulation-related intracerebral hemorrhage. JAMA 2015;313(8):824-836
16 Vermeer SE, Algra A, Franke CL, Koudstaal PJ, Rinkel GJ. Long-term prognosis after recovery from primary intracerebral hemorrhage. Neurology 2002;59(2):205-209

17 Izumihara A, Suzuki M, Ishihara T. Recurrence and extension of lobar hemorrhage related to cerebral amyloid angiopathy: multivariate analysis of clinical risk factors. Surg Neurol 2005;64(2):160-164

18 Hanger HC, Wilkinson TJ, Fayez-Iskander N, Sainsbury R. The risk of recurrent stroke after intracerebral haemorrhage. J Neurol Neurosurg Psychiatry 2007;78(8):836-840

19 Biffi A, Halpin A, Towfighi A, et al. Aspirin and recurrent intracerebral hemorrhage in cerebral amyloid angiopathy. Neurology 2010;75(8):693-698

\title{
Endovascular Coiling in a Patient with Chronic Kidney Disease-A Challenge for Anesthesiologist
}

\author{
Navneh Samagh ${ }^{1}$ Nidhi Singh ${ }^{2}$ Kiran Jangra ${ }^{2}$ Ajay Kumar ${ }^{3}$ \\ ${ }^{1}$ Department of Anesthesiology, All India Institute of Medical \\ Sciences, Bathinda, Punjab, India \\ 2Department of Anaesthesia and Intensive care, Postgraduate \\ Institute of Medical Education and Research, Chandigarh, India \\ Address for correspondence Kiran Jangra, DM, Department \\ of Anaesthesia and Intensive Care, 4th Floor, Nehru Hospital, \\ Postgraduate Institute of Medical Education and Research, \\ Chandigarh 160012, India (e-mail: drkiransharma0117@gmail.com).
}

${ }^{3}$ Department of Radiodiagnosis, Postgraduate Institute of Medical Education and Research, Chandigarh, India

J Neuroanaesthesiol Crit Care 2021;8:207-210.
Abstract
Keywords
- autosomal dominant polycystic kidney disease
- contrast induced nephropathy
- end-stage renal disease
- endovascular coiling
- iso-osmolar contrast medium

A 41-year-old male patient, a known case of autosomal dominant polycystic kidney disease (ADPCKD), presented to our institute with right middle cerebral artery aneurysm for which balloon-assisted endovascular coiling was planned. The major comorbidities were hypertension and end-stage renal disease (ESRD) on hemodialysis, twice weekly. Endovascular coiling was performed under general anesthesia, and special precautions were taken with regard to monitoring, fluid management, use of heparin, and contrast agent. The intraoperative and postoperative course was uneventful, and the patient was discharged after 7 days. In this report, various perioperative challenges of patients with chronic renal failure during coiling are discussed along with the measures to prevent the occurrence of contrast-induced nephropathy. published online

June 1, 2020
DOI https://doi.org/

$10.1055 / \mathrm{s}-0040-1712081$

ISSN 2348-0548. (c) 2020. Indian Society of Neuroanaesthesiology and Critical Care. This is an open access article published by Thieme under the terms of the Creative Commons Attribution-NonDerivative-NonCommercial-License, permitting copying and reproduction so long as the original work is given appropriate credit. Contents may not be used for commercial purposes, or adapted, remixed, transformed or built upon. (https://creativecommons.org/licenses/by-nc-nd/4.0/).

Thieme Medical and Scientific Publishers Pvt. Ltd. A-12, 2nd Floor, Sector 2, Noida-201301 UP, India 